$12-2013$

\title{
Particle retention in suspension-feeding fish after removal of filtration structures
}

Jennifer C. Smith

S. Laurie Sanderson

William and Mary, slsand@wm.edu

Follow this and additional works at: https://scholarworks.wm.edu/aspubs

Part of the Animal Experimentation and Research Commons

\section{Recommended Citation}

Smith, Jennifer C. and Sanderson, S. Laurie, Particle retention in suspension-feeding fish after removal of filtration structures (2013). Zoology, 116(6), 348-355.

https://doi.org/10.1016/j.zool.2013.08.008

This Article is brought to you for free and open access by the Arts and Sciences at W\&M ScholarWorks. It has been accepted for inclusion in Arts \& Sciences Articles by an authorized administrator of W\&M ScholarWorks. For more information, please contact scholarworks@wm.edu. 
Smith, J.C. and S.L. Sanderson. 2013. Particle retention in suspension-feeding fish after removal of filtration structures. Zoology 116: 348-355. doi: $10.1016 / j . z o o l .2013 .08 .008$

\section{Particle retention in suspension-feeding fish}

\section{after removal of filtration structures}

Jennifer C. Smith ${ }^{\text {a }}$, S. Laurie Sanderson*

Department of Biology, College of William \& Mary, Williamsburg, VA 23187-8795, USA

${ }^{\text {a }}$ Current address: College of Veterinary Medicine, Virginia Polytechnic Institute and State University, Blacksburg, VA 24061, USA

* Corresponding author.Tel.: +1 7572212123.

E-mail address: slsand@wm.edu (S.L.Sanderson).

Text pages: 29

Figures: 2

Graphs: 3

Keywords:

Filter feeding

Crossflow filtration

Suspension-feeding fish

Gill rakers 


\section{ABSTRACT}

The suspension-feeding cichlid fish Oreochromis aureus (blue tilapia) and Oreochromis esculentus (ngege tilapia) are able to selectively retain small food particles. The gill rakers and microbranchiospines of these species have been assumed to function as filters. However, surgical removal of these oral structures, which also removed associated mucus, did not significantly affect the total number of $11-200 \mu \mathrm{m}$ particles ingested by the fish. This result supports the hypothesis that the branchial arch surfaces themselves play an important role in crossflow filtration. Both species selectively retained microspheres greater than $50 \mu \mathrm{m}$ with gill rakers and microbranchiospines intact as well as removed, demonstrating that neither these structures nor mucus are necessary for size selectivity to occur during biological crossflow filtration. After removal of the gill rakers and microbranchiospines, O.esculentus retained significantly more microspheres 51-70 $\mu \mathrm{m}$ in diameter and fewer 91-130 $\mu \mathrm{m}$ microspheres compared to retention with intact structures, but the particle size selectivity of $O$. aureus was not affected significantly. These results support conclusions from previous computational fluid dynamics simulations indicating that particle size can have marked effects on particle trajectory and retention inside the fish oropharyngeal cavity during crossflow filtration. The substantial inter-individual variability in particle retention by suspension-feeding fish is an unexplored area of research with the potential to increase our understanding of the factors influencing particle retention during biological filtration. 


\section{Introduction}

Suspension-feeding fish that filter food particles as small as 5-3000 $\mu \mathrm{m}$ are key components of food webs and nutrient cycles, with the potential to structure plankton communities (e.g., Vinyard et al., 1988; Schaus et al., 2010; Annis et al., 2011). The diet of a suspension-feeding fish species and the size range of particles ingested should be dependent on the particle capture and retention mechanisms used by the species. The potential predictive power of this inference is high, but a paucity of data on particle capture and retention abilities and mechanisms in fish has hampered application. There is a rich literature on particle capture mechanisms in suspension-feeding invertebrates (review in Riisgård and Larsen, 2010). In contrast, of the more than 70 species (21 families) of ecologically and economically important fish species reported to suspension feed, data from experiments demonstrating the mechanisms used for particle capture and retention are available from only eight species in three families (Sanderson et al., 1991; Hoogenboezem et al., 1991; Sanderson et al., 2001; Callan and Sanderson, 2003). Among the relatively few fish species studied, there is extensive diversity in filtration morphology and mechanisms.

The objectives of our study were to (1) quantify the effects of surgical removal of gill rakers and microbranchiospines on particle retention by individual fish and (2) assess and compare the roles of these structures and the role of mucus during feeding in two suspension-feeding cichlid species, blue tilapia Oreochromis aureus (Steindachner) and ngege tilapia Oreochromis esculentus (Graham). Gill rakers are rows of comb-like, tufted, or knobby keratinous protuberances on branchial arches in the fish oropharyngeal cavity (Fig. 1). To exit from the oropharyngeal cavity, water must flow over and between the gill rakers. These structures may 
serve as a dead-end sieve retaining particles on the filter surface as water passes perpendicularly through the mesh, a sticky filter retaining particles that adhere to the filter elements, and/or a crossflow filter retaining particles in a concentrate that travels parallel to the filter surface. Gill rakers, and the associated microbranchiospines in cichlid fish, are assumed to function in food particle capture and retention but little data are available to test the multiple hypotheses proposed in the literature for their function during feeding. By modifying a novel approach used by Drenner et al. (1987), we compared particle retention ability and particle size selectivity before versus after surgical removal of the gill rakers and microbranchiospines from the branchial arches. Rather than quantifying particle retention by $O$. aureus and $O$. esculentus indirectly through aquarium water samples, we used a more direct method by measuring and counting microspheres that were excreted in the feces of the fish (Sanderson and Cech, 1995; Sanderson et al., 1998).

In fish species for which the gill rakers function as a dead-end mechanical sieve, particles that are too large to pass through the pores of the sieve will be captured and retained on the filter surface when water exits perpendicular to the sieve. While the spaces between the gill rakers of suspension-feeding cichlid fish are too large to capture the particles that are typically consumed by these species, minute microbranchiospines on cichlid branchial arches (Fig. 1) have been suggested as a potential dead-end sieve (Gosse, 1956; Drenner et al., 1987; Beveridge et al., 1988a, b). Experiments on suspension-feeding bream have indicated the use of gill rakers as a dead-end sieve in which the mesh size can be adjusted by movement of the gill rakers (Hoogenboezem et al., 1991, 1993). In such species, surgical removal of the gill rakers (and microbranchiospines if present) is predicted to result in profound changes in particle retention ability and particle size selectivity, as all particles that would have been captured and retained 
previously on the gill rakers or microbranchiospines that form the dead-end mechanical sieve will be lost after raker removal.

In contrast to dead-end mechanical sieving, a number of fluid mechanical processes during hydrosol filtration can result in contact between particles and a filter that has adhesive properties (Rubenstein and Kohl, 1977; LaBarbera, 1984; Shimeta and Jumars, 1991). Particles that are small enough to pass between filter elements may instead be captured and retained by adhesion to mucus that forms specific features such as sheets or strands and/or to sticky, mucus-covered structures such as gill rakers and microbranchiospines (Sanderson and Wassersug, 1990). Using high-speed fiberoptic endoscopy in live fish, two suspension-feeding species have been observed to capture and retain particles using mucus (Nile tilapia, Oreochromis niloticus, Sanderson et al., 1996; Sacramento blackfish, Orthodon microlepidotus, Sanderson et al., 1991). In such species, removal of the gill rakers and microbranchiospines is predicted to affect particle retention ability and particle size selectivity if this removal alters the presence of mucus that is involved in hydrosol filtration.

Crossflow filtration in either the presence or absence of mucus features such as sheets or strands is another mechanism that can result in the retention of particles that are small enough to pass between the filter elements of suspension-feeding fish (Sanderson et al., 2001; Ross et al., 2006; Motta et al., 2010; Paig-Tran et al., 2011). Crossflow filtration is used extensively for industrial processes such as water purification, processing of alcoholic beverages and fruit juices, and pharmaceutical manufacturing (Baker, 2012). During crossflow filtration in pump suspension-feeding fish, a high-velocity crossflow is pumped parallel to the gill rakers, generating a shear force and transporting suspended particles posteriorly towards the esophagus. As the oropharyngeal cavity narrows posteriorly, particles remain suspended in the crossflow 
and become more concentrated while filtrate must turn sharply to exit between the gill rakers (Sanderson et al., 2001). During fish crossflow filtration, particles rarely contact oropharyngeal cavity structures and do not accumulate on filter surfaces such as the branchial arches, gill rakers, microbranchiospines, or mucus. Endoscopic experiments have demonstrated crossflow filtration in five fish species (carp, Callan and Sanderson, 2003; ngege tilapia, gizzard shad, and goldfish, Sanderson et al., 2001; blue tilapia, Smith and Sanderson, 2007).

Inertial lift has been hypothesized as an important factor for maintaining particles in suspension during fish crossflow filtration so that the filter does not become fouled by particle accumulation (Sanderson et al., 2001; Smith and Sanderson, 2007). Due to this hydrodynamic force, particles initially near the tube or channel surfaces (e.g., gill rakers and branchial arches) lift away from these surfaces and migrate radially towards the center of the tube or channel (channel $\operatorname{Re}>1$ ) as the particles travel downstream (e.g., towards the esophagus) (Segré and Silberberg, 1962; Brandt and Bugliarello, 1966). Smith and Sanderson (2007) hypothesized that mucus on the branchial arches in $O$. aureus serves to increase crossflow speed and inertial lift by reducing the loss of water between the gill rakers and between the branchial arches.

Whereas $O$.aureus uses crossflow filtration in the presence of mucus sheets and strands (Smith and Sanderson, 2007), O. esculentus uses crossflow filtration without the presence of mucus (Goodrich et al., 2000). Both O. aureus and O. esculentus consume phytoplankton in the field, but $O$. aureus also consumes a much wider range of prey (e.g., Drenner et al., 1984; Batjakas et al., 1997). Particle retention abilities have not been quantified previously in species known to use crossflow filtration. If the gill rakers and microbranchiospines are essential for crossflow filtration in the oropharyngeal cavities of $O$. aureus and O. esculentus, removal of these structures will have marked effects on particle retention ability and particle size selectivity. 
Additionally, in fish species such as $O$. aureus for which mucus has been hypothesized to contribute to inertial lift during crossflow filtration (Smith and Sanderson, 2007), removal of the gill rakers and microbranchiospines is predicted to affect particle retention if this removal alters the presence of mucus.

\section{Materials and methods}

\subsection{Design of feeding experiments}

The animal care procedures and experimental protocol were approved by the Institutional Animal Care and Use Committee (IACUC-406), College of William \& Mary. O. aureus were obtained from pure stock raised at the University of Arizona. O. esculentus were from pure stock bred at the Museum of Science in Boston. Tilapia were maintained at a temperature of 25$28^{\circ} \mathrm{C}$ on a diet of Tetramin ${ }^{\mathrm{TM}}$ flakes in 110-L aquaria with a gravel substrate. Fish were identified individually using natural external markings and by clipping the tip of a single dorsal fin spine.

Experiments were conducted on five adult $O$. aureus $(22.7-27.7 \mathrm{~cm}$ standard length, SL) and five adult $O$. esculentus (15.7-19.1 cm SL) to determine the size frequency distribution of particles retained during suspension feeding for each species. The design of the feeding experiments was modified from Sanderson and Cech (1995; Sanderson et al., 1998). A 110-L experimental aquarium was filled with $60 \mathrm{~L}$ of tap water that had been measured using a $1 \mathrm{~L}$ graduated cylinder. To ensure water circulation, a submersible water pump (Little Giant, 304 L/h; 4 pumps total) was attached to each end of two tygon tubes $(1.2 \mathrm{~cm}$ i.d., $1.5 \mathrm{~cm}$ o.d., $40 \mathrm{~cm}$ long) that had been threaded through metal rings attached to the bottom of the aquarium. The metal rings held the tygon tubing flat along the aquarium bottom. Throughout the feeding 
experiments, the pumps forced water out of holes ( $2 \mathrm{~mm}$ diameter) drilled along the length of the tubing. The flow did not disrupt the fish, but was sufficient to prevent particles from settling. Three air stones (Aquamist, $1.5 \times 2.5 \mathrm{~cm}$ ) were used at the corners of the aquarium as an additional method to maintain particles in suspension.

At the beginning of each experiment, a solution of microspheres composed of inert, crosslinked Dextran polymer was added to achieve a concentration of approximately 10 particles $/ \mathrm{mL}$ in the aquarium (Sigma Aldrich Sephadex G-25 beads; 20-50 $\mu \mathrm{m}$ diameter, $0.01 \mathrm{~g} ; 50-150 \mu \mathrm{m}$ diameter, $0.165 \mathrm{~g}$; weighed to the nearest $0.001 \mathrm{~g}$ ). Microspheres were hydrated in tap water for $24 \mathrm{~h}$ prior to each experiment. We established that there was no additional swelling after the initial hydration period by hydrating a sample of microspheres for up to $42 \mathrm{~h}$, and measuring the diameter of the microspheres at $8 \mathrm{~h}$ intervals.

Each fish was then placed individually in the aquarium described above and allowed to suspension feed for 3.00 min on an aqueous slurry of Tetramin flakes which mixed with the microspheres in the aquarium. The slurry was added to the aquarium via a short piece of tubing attached to a $30 \mathrm{~mL}$ syringe. Físh suspension fed as the food particles drifted through the water column. The aquarium water was stirred periodically with a rod as an additional method to ensure suspension of the food particles and microspheres. After 3.00 min of feeding, whole Tetramin flakes were added to the aquarium by hand, and the fish continued to suspension feed on the aquarium mixture of Tetramin slurry, Tetramin flakes, and microspheres for $1.00 \mathrm{~min}$. Fish were videotaped during the experiments using a handheld Sony CCD-TR81 video camera recorder $\left(30\right.$ frames $\left.\mathrm{s}^{-1}\right)$.

At the conclusion of each feeding experiment, the fish was removed from the aquarium and placed in an 18.9 L bucket of fresh tap water. Each fish was then held over the bucket in a soft 
net and rinsed externally with fresh tap water from a squirt bottle to remove any microspheres trapped in external mucus. Subsequently, the water in this initial bucket was discarded and each fish was placed individually in a heated and aerated holding tank $(27.8 \mathrm{~L}$ for O.esculentus, 55.6 L for $O$. aureus). Plastic grating at the bottom of the holding tank prevented the feces from being resuspended by the activity of the fish. Within several hours, the fish was transferred temporarily to a fresh bucket of water and fed whole Tetramin flakes. All feces were then collected from the holding tank using a pipette and placed under coverslips on glass microscope slides moistened with water. The holding tank was filled with fresh tap water and the fish was returned. Any feces that the fish produced in the temporary bucket of water were also collected and placed on microscope slides. This entire process was repeated four or five times at approximately $12 \mathrm{~h}$ intervals, until the feces were devoid/of microspheres. The fish was then returned to its aquarium. All of the fish continued to eat and remained healthy.

An Olympus BH2 phase contrast light microseope with an ocular micrometer was used to scan entire microscope slides systematically at 10x along each row. Microspheres were measured at 20x to the nearest $5 \mu \mathrm{m}$. The microspheres were encased in a thin transparent sheath that surrounded the fecal strings, and the outlines of microspheres were clearly visible in the field of view as circles. Preliminary experiments on three individuals established that particle size was not related to day of feces collection (i.e., neither smaller nor larger microspheres were defecated first). Approximately 600 microspheres were measured from microscope slides selected randomly for each fish. In addition to the 600 measured microspheres, for three fish of each species the total number of microspheres retained on all microscope slides prepared from that fish was counted to aid later in quantifying particle 
retention ability. If a total of less than 600 microspheres was retained by an individual, all retained microspheres were counted and measured.

\subsection{Removal of gill rakers and microbranchiospines}

Approximately 7 days after the first round of feeding experiments, gill rakers and microbranchiospines (Fig. 1) were removed from each fish. The method of removal was modified from that of Drenner et al. (1987). O. aureus and O. esculentus were anesthetized with MS-222 and the tissue supporting all lateral and medial gill rakers and all microbranchiospines was removed with microforceps from the anterior four branchial arches on each side of five fish for each species. We refer to this procedure as "gill raker removal", although all microbranchiospines and gill rakers were removed. The fifth branchial arch forms the lower pharyngeal jaw, which was left unaltered.

Whereas Drenner et al. (1987) reported that the rows of gill rakers and microbranchiospines of Tilapia galilaea (current name Sarotherodon galilaeus) were surgically stripped during a procedure with a mean duration of $22.7 \mathrm{~min}$, approximately $90 \mathrm{~min}$ per fish were needed to perform our procedure of gradually pulling thin sheets of tissue bearing all gill rakers and microbranchiospines from the branchial arches. During this time, the fish was lifted periodically from the water containing MS-222 in the surgery tray to remove a section of gill rakers and microbranchiospines under a magnifying glass, and then returned to the water in the surgery tray. Following the surgery, the fish was returned to its holding aquarium and Fungus Eliminator (Jungle Laboratories Corporation) was added once to prevent infection. Twelve days after gill raker removal, the feeding experiments described above were repeated on the same individuals. 


\subsection{Particle retention ability}

Rather than measure the decline in microsphere concentration in the aquarium water, we analyzed three fish of each species for particle retention ability directly by counting all microspheres in the feces of each individual from the feeding experiments. This technique, which has been performed previously with juvenile but not adult fish, permitted the detection of small as well as large numbers of retained microspheres and enabled quantification of differences between and within individuals (Sanderson and Cech, 1995; Sanderson et al., 1998).

For O.aureus and O.esculentus, the total number of microspheres retained by each individual with intact gill rakers was compared to the total number retained by that individual after gill raker removal. The videotapes from the feeding experiments before and after raker removal were analyzed to quantify the number of video frames during which each individual fish was suspension feeding with characteristic repetitive pumping actions that are distinct from ventilation (Sanderson et al., 1996; Goodrich et al., 2000; Smith and Sanderson, 2007). Next, the total number of these feeding pumps was divided by the total time that each individual was observed to be feeding during each experiment to determine any change in pumping rate (pumps $\mathrm{s}^{-1}$ ) that may have contributed to a change in particle retention. For example, a decrease in the rate of feeding pumps (i.e., fewer pumps $\mathrm{s}^{-1}$ ) after gill raker removal could result in a decrease in particle retention.

\subsection{Scanning electron microscopy}

To obtain images documenting gill raker and microbranchiospine removal, the gill arch tissue supporting all lateral and medial gill rakers and microbranchiospines was removed with microforceps as described above from the anterior four branchial arches on the right side only of 
one O.aureus $(22.8 \mathrm{~cm} \mathrm{SL})$ and one O. esculentus $(17.7 \mathrm{~cm} \mathrm{SL})$ specimen that were not included in the feeding experiments. Fifteen days after surgical removal of the gill rakers and microbranchiospines, the fish were euthanized with MS-222 and the first and second gill arches from both sides of each fish were cut into two or three equal sections using a razor blade over dental wax. To ensure correct orientation under the scanning electron microscope (SEM), the ventral gill filaments of each section were trimmed to be noticeably longer than the dorsal filaments. A vigorous rinse with tap water from a laboratory squirt bottle removed any loose mucus from the sections that had rakers attached.

The arch sections were fixed with $2.5 \%$ gluteraldehyde in $0.1 \mathrm{M}$ phosphate buffer $(\mathrm{pH} 7.2-$ 7.4) for $30 \mathrm{~min}$ at room temperature. Following refrigeration in the fixative at $4^{\circ} \mathrm{C}$ for $2 \mathrm{~h}$, the sections were rinsed three times in the $0.1 \mathrm{M}$ phosphate buffer. As recommended by Dobbs (1972), this was followed by a detritus/mucus-stripping procedure. First, each section was treated with $16 \%$ glycerol for $24 \mathrm{~h}$ at $4^{\circ} \mathrm{C}$. Next, the sections were bathed in $20 \%$ ethanol for 24 h at $4^{\circ} \mathrm{C}$.

The sections were then dehydrated at room temperature through an ethanol series for $15 \mathrm{~min}$ at each of the following ethanol concentrations: $50 \%, 70 \%, 80 \%, 95 \%, 100 \%, 100 \%, 100 \%$. Sections remained in $100 \%$ ethanol for approximately three days before a chemical drying agent (hexamethyldisilazane, HMDS) was applied. O.esculentus sections were dried with HMDS for 5 min, while $O$. aureus sections remained in HMDS for 10 min due to their thickness. The samples were fixed while still damp to metal stubs using standard adhesive and silver paint. The stubs were sputter coated with a $20 \mathrm{~nm}$ layer of gold-palladium at $7 \mathrm{~nm} \min ^{-1}$ (Hummer Vii sputtering system) and stored in a desiccation chamber. Each arch section was observed using an AMRAY 1810 SEM at magnifications from 20-100x. 


\subsection{Data analysis}

Levene's tests for homogeneity of variance were performed. Data from the two species on amount of time spent feeding, pumping rate, and number of particles retained were then analyzed using repeated measures ANOVAs with the repeated measure specified as being before versus after gill raker and branchiospine removal. As there were no significant interaction effects, the variables in each ANOVA were examined independently.

A replicated goodness of fit test ( $G$-statistic) was used to compare the particle size frequency distributions quantified from the feces of each species before removal of gill rakers and microbranchiospines (observed distribution) versus the size frequency distribution that was fed to the fish (expected distribution). Kolmogorov-Smirnov tests compared particle size frequency distributions between species as well as before versus after removal of gill rakers and microbranchiospines within species.

\section{Results}

\subsection{Feeding behavior and kinematics}

Fish were not adversely affected by the removal of gill rakers. The tissue on the branchial arches healed completely to form a smooth layer lacking any remnants of the gill rakers or microbranchiospines (Fig. 2). Overall feeding behavior appeared to be comparable after versus before gill raker removal, and food (Tetramin ${ }^{\mathrm{TM}}$ slurry and flakes) was not observed to be lost from the oral or opercular cavities following surgery.

During the experiments, the amount of time that the fish were observed to be feeding in the videotapes did not differ significantly between species or after versus before gill raker removal 
(repeated measures ANOVA, $\mathrm{df}=1,4 ; P=0.19, P=0.35$, respectively). Pumping rate after versus before raker removal did not differ significantly within species (repeated measures ANOVA, $P=0.13$, Fig. 3). However, the rate of feeding pumps (pumps s ${ }^{-1}$ ) was significantly higher in O. esculentus than in O. aureus (repeated measures ANOVA, $\mathrm{df}=1,4 ; P=0.003$, Fig. $3)$.

\subsection{Particle retention ability}

O. esculentus retained significantly fewer particles than $O$. aureus, before as well as after gill raker removal (repeated measures ANOVA, $\mathrm{df}=1,4 ; P=0.03$, Fig. 4). There was not a significant difference between the number of particles retained before versus after raker removal $(P=0.69$, Fig. 4). However, for five of the six individuals, the number of microspheres retained after gill raker removal was less than the number of microspheres retained with gill rakers intact. One $O$. aureus specimen retained substantially more microspheres after gill raker removal.

\subsection{Particle size selectivity}

Particle size selectivity analyses were conducted for each species by measuring 600 microspheres on microscope slides chosen randomly from each of five individuals before vs. after gill raker removal. The size frequency distributions of microspheres retained by $O$. aureus and $O$.esculentus before and after gill raker removal differed significantly from the size frequency distribution in the aquarium water during the feeding experiments (replicated goodness of fit tests; total, pooled, and heterogeneity $G, P<0.001$, Fig. 5). With intact gill rakers, both species retained proportionately fewer microspheres $\leq 50 \mu \mathrm{m}$ in diameter than were present in the aquarium water, but proportionately more microspheres $51-110 \mu \mathrm{m}$ in diameter 
than were in the water. Although only $55 \%$ of the microspheres in the aquarium water were greater than $50 \mu \mathrm{m}, 70 \%$ of the microspheres ingested by $O$. aureus with intact rakers and $78 \%$ ingested by $O$. esculentus with intact rakers were greater than $50 \mu \mathrm{m}$.

The size frequency distributions of microspheres ingested by $O$. aureus and O. esculentus did not differ significantly when both species had intact gill rakers and microbranchiospines (Kolmogorov-Smirnov test, $P>0.05$ ). Similarly, the size frequency distribution of microspheres retained by $O$. aureus with intact structures did not differ significantly from the size frequency distribution following removal of these structures (Kolmogorov-Smirnov test, $P>0.05$, Fig. 5A). However, removal of the gill rakers and microbranchiospines led to a significant change in the size frequency distribution of microspheres retained by $O$. esculentus. O. esculentus retained a significantly higher proportion of 51-70 $\mu \mathrm{m}$ microspheres and a significantly lower proportion of 91-130 $\mu \mathrm{m}$ microspheres following gill raker and microbranchiospine removal compared with retention when these structures were intact (Kolmogorov-Smirnov test, $P<0.01$, Fig. 5B). Related to this result, removal of the gill rakers and microbranchiospines resulted in a significant difference between the size frequency distributions of particles retained by $O$. esculentus and $O$. aureus. Following removal of these structures from both species, O. esculentus retained a significantly higher proportion of 51-90 $\mu \mathrm{m}$ microspheres and a significantly lower proportion of 111-130 $\mu \mathrm{m}$ microspheres compared to O. aureus (Kolmogorov-Smirnov test, $P<0.05$ ).

\section{Discussion}

\subsection{Dead-end sieving in suspension-feeding fish}

Dead-end mechanical sieving has generally been assumed to be the primary method of particle capture and retention in suspension-feeding fish (review in Gerking, 1994). However, 
dead-end sieving has been reported in experiments on one species only (bream, Abramis brama, Cyprinidae, Hoogenboezem et al., 1991). While higher gill raker numbers and/or smaller gaps between gill raker structures have been associated frequently with the consumption of smaller planktonic prey (e.g., Shoup and Hill, 1997; Friedland et al., 2006; Kahilainen et al., 2011), data on the actual prey sizes consumed have rarely been consistent with predictions based on the sizes of the spaces between gill raker structures (e.g., Seghers, 1975; Wright et al., 1983; Langeland and Nøst, 1995; Lynch et al., 2010; but see Mummert and Drenner, 1986). In fish that use either hydrosol filtration with mucus entrapment or crossflow filtration rather than dead-end sieving, the sizes of the gaps between gill raker structures do not necessarily serve as prey size thresholds (Sanderson et al., 2001).

In species for which the gill rakers and/or microbranchiospines function as a dead-end sieve, gill raker and microbranchiospine removal will lead to marked changes in particle retention because the structures that form the dead-end sieve will have been eliminated. Consistent with the results of high-speed video endoscopy indicating that neither gill rakers nor microbranchiospines serve as a dead-end sieve in O. aureus and O. esculentus (Smith and Sanderson, 2007; Goodrich et al., 2000, Sanderson et al., 2001), removal of gill rakers and microbranchiospines from these species did not result in extensive changes in particle retention and size selectivity. Our results confirm that neither gill rakers nor microbranchiospines operate as a dead-end sieve in $O$. aureus and $O$. esculentus.

Drenner et al. (1987) reported that surgical removal of the gill rakers only, the microbranchiospines only, or both the gill rakers and microbranchiospines had no significant effect on particle ingestion rates or selectivity of microspheres $(4-70 \mu \mathrm{m})$ in the cichlid Sarotherodon galilaeus. However, they noted that these branchial structures had partially 
regenerated to form protuberances of abnormal size, shape, and position at the time of the feeding experiments two weeks after the surgery. Our results on the cichlids $O$. aureus and $O$. esculentus (Fig. 5), which had not begun to regenerate these structures when the experiments were conducted $12 \mathrm{~d}$ after surgery (Fig. 2), support Drenner et al.'s (1987) conclusion that the partially regenerated structures in S. galilaeus were unlikely to have been responsible for continued particle retention by serving as a mechanical dead-end sieve.

\subsection{Functions of mucus in particle retention by suspension-feeding fish}

Mucus is ubiquitous on fish epidermal surfaces, including the oropharyngeal cavity (Shephard, 1994). Structures can be coated with a thin layer of transparent mucus that may not be detected visually (Beninger et al., 1992). When removal of the gill rakers and microbranchiospines did not affect particle ingestion ratés or size selectivity in S. galilaeus, Drenner et al. (1987) noted that mucus entrapment might be responsible for the ability of $S$. galilaeus to retain particles in the absence of gill rakers and microbranchiospines. Northcott and Beveridge (1988) examined the ultrastructure and histology of the branchial arches and gill rakers in the Nile tilapia,Oreochromis niloticus, and proposed that mucus produced from the gill rakers could act as a particle entrapment mechanism in the pores of the branchial sieve. Highspeed video endoscopy later demonstrated that $O$. niloticus uses mucus strands and aggregates resting on the gill rakers and branchial arches to capture and retain small particles $(<1.0 \mathrm{~mm})$ during hydrosol filtration (Sanderson et al., 1996).

Even when visible as sheets, strands, and/or aggregates, mucus does not always serve to capture particles during fish suspension feeding. Although visible mucus is abundant in $O$. aureus with intact gill rakers, this mucus does not contribute substantially to particle entrapment 
(Smith and Sanderson, 2007). High-speed video endoscopy demonstrated that $O$. aureus uses crossflow filtration in the presence of mucus on the branchial arches and gill rakers. Mucus in O. aureus with intact gill rakers was observed more than $50 \%$ of the time during feeding, in the form of sheets, strands, or aggregates attached to the branchial arches and gill rakers and then lifting to move to the posterior oral cavity (Smith and Sanderson, 2007). However, 98\% of the food particles $(0.1-1.0 \mathrm{~mm})$ were seen to travel independently in a straight path towards the posterior oral cavity of $O$. aureus without being retained in mucus. These particles were not observed to swirl inside the oral cavities of O. aureus and O. esculentus (Sanderson et al., 2001; Smith and Sanderson, 2007).

Surgical removal of the gill rakers and microbranchiospines in O. aureus resulted in a lack of visible mucus inside the oropharyngeal cavity, presumably due to removal of the mucussecreting branchial tissue (Smith and Sanderson, 2007). Following surgical removal of these structures, Smith and Sanderson $(2007,2008)$ reported endoscopic data on continuing crossflow filtration in $O$. aureus with a decreased water flow speed along the branchial arches. More particles were observed in endoscopic videos to be lost with the flow exiting between the branchial arches in the absence of gill rakers and microbranchiospines (15\%) than with gill rakers intact (8\%), although this difference was not statistically significant (Smith and Sanderson, 2007).

When the gill rakers and microbranchiospines were removed in the current study, particle retention and size selectivity in $O$. aureus did not change significantly (Figs. 4, 5). This result supports the hypothesis that the branchial arch surfaces themselves play an important role in crossflow filtration, independent of the roles that the gill rakers, microbranchiospines, and branchial mucus may serve (Smith and Sanderson, 2007). Hypotheses for the generation of 
patterns in fluid flow through the oropharyngeal cavity are currently being tested using physical models.

As the absence of visible mucus in O. aureus did not significantly affect particle retention or size selectivity, our results do not support the hypotheses proposed by Smith and Sanderson $(2007,2008)$ that mucus on the branchial structures in O. aureus functions to regulate the loss of water from the oropharyngeal cavity and contributes to crossflow speed and inertial lift. Therefore, the function of the abundant mucus on the branchial arches of $O$. aureus remains unclear.

\subsection{Particle size selectivity in O. esculentus following gill raker removal}

O. esculentus uses crossflow filtration in the absence of visible mucus (Goodrich et al., 2000; Sanderson et al., 2001). After removal of the gill rakers and microbranchiospines, O. esculentus retained a significantly higher proportion of microspheres $51-70 \mu \mathrm{m}$ in diameter and lower proportion of 91-130 $\mu \mathrm{m}$ microspheres compared to retention with intact structures (Fig. 5B). With intact gill rakers and microbranchiospines, $44.6 \pm 5.5 \%$ of the microspheres ingested by $O$. esculentus were smaller than $70 \mu \mathrm{m}$, whereas $49.8 \pm 5.2 \%$ of the microspheres ingested were smaller than $70 \mu$ m after remoyal of these structures (mean \pm S.D., $\mathrm{n}=5$ ).

The number of particles retained by O. esculentus in these feeding experiments was significantly lower than that of O.aureus (Fig. 4), and all three O.esculentus retained fewer particles after versus before gill raker removal. Therefore, the subtle but statistically significant shift in the size frequency distribution towards the retention of particles smaller than $70 \mu \mathrm{m}$ in $O$. esculentus after gill raker removal (Fig. 5B) reflects a decreased ability to select for larger particles, rather than an increased ability to retain smaller particles. Computational fluid 
dynamics simulations by Cheer et al. (2012) demonstrated that particle size can have substantial effects on particle trajectory and retention inside the oropharyngeal cavity during crossflow filtration. After surgical removal of the gill rakers, increased flow volume between the branchial arches and a resultant decrease in crossflow speed and inertial lift inside the oropharyngeal cavity could result in the loss of larger particles between the branchial arches (Smith and Sanderson, 2008; Cheer et al., 2012).

Unlike the case in O.esculentus, particle size selectivity in $O$. aureus did not change significantly following the removal of gill rakers and microbranchiospines (Fig. 5).

Consequently, particle size selectivity differed significantly between $O$. esculentus and $O$. aureus after gill raker removal. This may be due to the generation of different intraoral flow speeds in O. aureus compared to O. esculentus, or may be related to the greater variability among individual O. aureus (Figs. 4, 5).

\subsection{Diet and particle size in O. aureus and O. esculentus}

O. esculentus tends to have a specialized diet with diatoms or suspended colonial algae as the primary components (Onyari, 1983; Opiyo and Dadzie, 1994; Batjakas et al., 1997), whereas $O$. aureus tends to be an opportunistic omnivore that consumes a much wider range of prey, including phytoplankton, detritus, zooplankton, benthic invertebrates, and macrophytes (Spataru and Zorn, 1978; Drenner et al., 1984; Mallin, 1985). By quantifying ingestion rates and net energy returns in the laboratory for O. aureus, Yowell and Vinyard (1993) developed a model predicting that suspension feeding by adult $O$. aureus on phytoplankton will be more profitable than particulate feeding on zooplankton under most circumstances. 
In laboratory experiments, O. esculentus $(9-15 \mathrm{~cm}$ total length) retained 3-celled and 4-celled Scenedesmus phytoplankton colonies (c.30 $\mu \mathrm{m}$ x $18 \mu \mathrm{m})$ but did not retain 1- or 2-celled Scenedesmus (Batjakas et al., 1997). When fed the phytoplankton Chlamydomonas $(6-15 \mu \mathrm{m})$, O. aureus ingested this unicellular alga inefficiently and lost weight (McDonald, 1987). Drenner et al. (1984) reported that $O$. aureus $(4.3-18.7 \mathrm{~cm} \mathrm{SL})$ selectively fed on polystyrene microspheres $>25 \mu \mathrm{m}$. These results are consistent with our findings that, although $O$. esculentus (15.7-19.1 cm SL) and O. aureus $(22.7-27.7 \mathrm{~cm} \mathrm{SL})$ were able to retain particles as small as $11 \mu \mathrm{m}$, they preferentially retained particles larger than $50 \mu \mathrm{m}$ with gill rakers intact as well as removed (Fig. 5).

\subsection{Variability among individuals in particle retention}

The standard experimental design is to place a group of suspension-feeding fish together in one aquarium and quantify particle retention by the group. In the current study, placing each individual fish in a separate aquarium and collecting all ingested particles from the feces of each fish allowed documentation of substantial variability in particle retention among individuals (Figs. 4, 5). Smith and Sanderson (2008) observed similar inter-individual variability in the oral flow speed of $O$. aureus, which could be related to the variability in particle retention. Changes in factors that are under the control of individual fish, such as oral flow speed and the angle at which flow approaches the gill rakers, have profound effects in physical models and in computational fluid dynamics simulations of flow patterns and particle movement inside the oropharyngeal cavity (Cheer et al., 2004, 2012; Paig-Tran et al., 2011).

During pump suspension feeding, substantial inter- and intra-individual variability in oral flow speed, branchial arch abduction, suction generation, pumping rate, and mucus production 
may provide a highly flexible filtration system that can be adjusted depending on the environment and needs of the individual. For example, endoscopic data indicate that $O$. niloticus can adjust mucus secretion rates in response to particles of the same composition but different size (Sanderson et al., 1996). Individual variability in filtration processes remains an unexplored area of research with substantial potential for increasing our understanding of the factors that influence particle retention by suspension-feeding fish.

\subsection{Role of gill rakers and microbranchiospines in suspension-feeding fish}

Are the gill rakers and microbranchiospines important in $O$. aureus and $O$. esculentus? Although removal of these structures in O. esculentus led to only a small reduction in the retention of particles larger than $70 \mu \mathrm{m}$ (Fig. 5B), such a decline could be of biological relevance over a $24 \mathrm{hr}$ period. In addition, Drenner et al. (1987) noted other potential functions for these structures, such as the retention of eggs and fry by gill rakers in these mouth-brooding cichlids and the protection of gill filaments by microbranchiospines.

Pump suspension-feeding cíchlids are the only species from which the gill rakers have been removed experimentally Similar experiments on ram suspension-feeding species and pump suspension-feeding species in other fish families with elongated comb-like gill rakers could result in marked impacts on fluid flow and particle retention.

\section{Acknowledgements}

We thank K. Baxter, D. Cunningham, K. Douglas, A. Kepple, C. Lemon, G. McConnell, M. Mirabella, and D. Suskin for data collection and analysis, R. Drenner and D. Hambright for advice on gill raker removal, and P. Heideman for statistical expertise. J. Scott and E. Orlova 
provided technical advice for the scanning electron microscopy, and K. Nolan photographed the SEMs in Fig. 2. L. Stevens (Boston Museum of Science) and K. Fitzsimmons (University of Arizona) assisted in obtaining specimens. The research was supported by NSF grant IBN0131293 and a grant from the Thomas F. Jeffress and Kate Miller Jeffress Memorial Trust to S.L. Sanderson. 


\section{References}

Annis, E.R., Houde, E.D., Harding, Jr., L.W., Mallonee, M.E., Wilberg, M.J., 2011. Calibration of a bioenergetics model linking primary production to Atlantic menhaden Brevoortia tyrannus growth in Chesapeake Bay. Mar. Ecol. Prog. Ser. 437, 253-267.

Baker, R.W., 2012. Membrane Technology and Applications, 3rd ed. John Wiley \& Sons, Chichester.

Batjakas, I.E., Edgar, R.K., Kaufman, L.S., 1997. Comparative feeding efficiency of indigenous and introduced phytoplanktivores from Lake Victoria: experimental studies on Oreochromis esculentus and Oreochromis niloticus. Hydrobiologia 347, 75-82.

Beninger, P.G., Ward, J.E., MacDonald, B.A., Thompson, R.J., 1992. Gill function and particle transport in Placopecten magellanicus (Mollusca: Bivalvia) as revealed using video endoscopy. Mar. Biol. 114, 281-288.

Beveridge, M.C.M., Briggs, M.R.P., Mowat, A., Northcott, M.E., Ross, L.G., 1988a. The function of microbranchiospines in tilapias. In: Pullin, R.S.V., Bhukaswan, T., Tonguthai, K., Maclean, J.L. (Eds.), The Second International Symposium on Tilapia in Aquaculture, ICLARM Conference Proceedings. Department of Fisheries, Bangkok and International Center for Living Aquatic Resources Management, Manila. Vol. 15, pp. 311-317.

Beveridge, M.C.M., Briggs, M.R.P., Mowat, A., Northcott, M.E., Ross, L.G., 1988b. The occurrence, structure, and development of microbranchiospines among the tilapias (Cichlidae: Tilapiini). Can. J. Zool. 66, 2564-2572.

Brandt, A., Bugliarello, G., 1966. Concentration redistribution phenomena in the shear flow of monolayers of suspended particles. Trans. Soc. Rheol. 10, 229-251. 
Callan, W.T., Sanderson, S.L., 2003. Feeding mechanisms in carp: crossflow filtration, palatal protrusions and flow reversals. J. Exp. Biol. 206, 883-892.

Cheer, A., Cheung, S., Hung, T.-C., Piedrahita, R.H., Sanderson, S.L., 2012. Computational fluid dynamics of fish gill rakers during crossflow filtration. Bull. Math. Biol. 74, 981-1000.

Cheer, A.Y., Cheung, S., Sanderson, S.L., 2004. Computational fluid dynamics of crossflow filtration in suspension-feeding fishes. In Proceedings of the third international conference on computational fluid dynamics (ICCFD3), Vol. 3, Springer, Berlin, pp. 81-87.

Dobbs, D.H., 1972. A method for preservation of soft tissues of marine teleosts for scanning electron microscopy. Tissue and Cell 4, 687-690.

Drenner, R.W., Taylor, S.B., Lazzaro, X., Kettle, D., 1984,Particle-grazing and plankton community impact of an omnivorous cichlid. Trans. Am. Fish. Soc. 113, 397-402.

Drenner, R.W., Vinyard, G.L., Hambright, K.D., Gophen, M., 1987. Particle ingestion by Tilapia galilaea is not affected by removal of gill rakers and microbranchiospines. Trans. Am. Fish. Soc. 116, 272-276.

Friedland, K.D., Ahrenholz, D.W., Smith, J.W., Manning, M., Ryan, J., 2006. Sieving functional morphology of the gill raker feeding apparatus of Atlantic menhaden. J. Exp. Zool. 305A, 974-985.

Gerking, S.D., 1994. Feeding Ecology of Fish. Academic Press, San Diego.

Goodrich, J.S., Sanderson, S.L., Batjakas, I.E., Kaufman, L.S., 2000. Branchial arches of suspension-feeding Oreochromis esculentus: sieve or sticky filter? J. Fish Biol. 56, 858-875.

Gosse, J.P., 1956. Dispositions speciales de l'appareil branchial des Tilapia et Citharinus. Annls. Soc. r. zool. Belg. 86, 303-308. 
Hoogenboezem, W., van den Boogaart, J.G.M., Sibbing, F.A., Lammens, E.H.R.R., Terlouw, A., Osse, J.W.M., 1991. A new model of particle retention and branchial sieve adjustment in filter-feeding bream (Abramis brama) (Cyprinidae). Can. J. Fish. Aquat. Sci. 48, 7-18.

Hoogenboezem, W., Lammens, E.H.R.R., MacGillavry, P.J., Sibbing, F.A., 1993. Prey retention and sieve adjustment in filter-feeding bream (Abramis brama) (Cyprinidae). Can. J. Fish. Aquat. Sci. 50, 465-471.

Kahilainen, K.K., Siwertsson, A., Gjelland, K.Ø., Knudsen, R., Bøhn, T., Amundsen, P.-A., 2011. The role of gill raker number variability in adaptive radiation of coregonid fish. Evol. Ecol. 25, 573-588.

LaBarbera, M., 1984. Feeding currents and particle capture mechanisms in suspension feeding animals. Am. Zool. 24, 71-84.

Langeland, A., Nøst, T., 1995. Gill raker structure and selective predation on zooplankton by particulate feeding fish. J. Fish Biol. 47, 719-732.

Lynch, P.D., Brush, M.J., Condon, E.D., Latour, R.J., 2010. Net removal of nitrogen through ingestion of phytoplankton by Atlantic menhaden Brevoortia tyrannus in Chesapeake Bay. Mar. Ecol. Prog. Ser.401, 195-209.

McDonald, M.E., 1987. Interactíons between a phytoplanktivorous fish, Oreochromis aureus, and two unialgal forage populations. Env. Biol. Fish. 18, 229-234.

Mallin, M.A., 1985. The feeding ecology of the blue tilapia (T. aurea) in a North Carolina reseryoir. Proceedings of the Conference and International Symposium on Applied Lake and Watershed Management 5, 323-326.

Motta, P.J., Maslanka, M., Hueter, R.E., Davis, R.L., de la Parra, R., Mulvany, S.L., Habegger, M.L., Strother, J.A., Mara, K.R., Gardiner, J.M., Tyminski, J.P., Zeigler, L.D., 2010. Feeding 
anatomy, filter-feeding rate, and diet of whale sharks Rhincodon typus during surface ram filter feeding off the Yucatan Peninsula, Mexico. Zoology 113, 199-212.

Mummert, J.R., Drenner, R.W., 1986. Effect of fish size on the filtering efficiency and selective particle ingestion of a filter-feeding clupeid. Trans. Am. Fish. Soc. 115, 522-528.

Northcott, M.E., Beveridge, M.C.M., 1988. The development and structure of pharyngeal apparatus associated with filter feeding in tilapias (Oreochromis niloticus). J. Zool., Lond. 215, 133-149.

Onyari, J.M., 1983. A review of the biology of tilapia species in Lake Victoria with special reference to its feeding and breeding habits. Kenya Aquatica 1, 39-54.

Opiyo, S.V., Dadzie, S., 1994. Diet and food utilization in Oreochromis esculentus (Graham) in Lake Kanyaboli, Kenya. Fish. Manage. Ecol.1, 79-90.

Paig-Tran, E.W.M., Bizzarro, J.J., Strother, J.A., Summers, A.P., 2011. Bottles as models: predicting the effects of varying swimming speed and morphology on size selectivity and filtering efficiency in fishes. J. Exp. Biol. 214, 1643-1654.

Riisgård, H.U., Larsen, P.S., 2010. Particle capture mechanisms in suspension-feeding invertebrates. Mar. Ecol. Prog. Ser. 418, 255-293.

Ross, L.G., Martínez-Palacios, C.A., Aguilar Valdez, Ma. del C., Beveridge, M.C.M., Chavez Sanchez,Ma.C., 2006. Determination of feeding mode in fishes: the importance of using structural and functional feeding studies in conjunction with gut analysis in a selective zooplanktivore Chirostoma estor estor Jordan 1880. J. Fish Biol. 68, 1782-1794.

Rubenstein, D.I., Koehl, M.A.R., 1977. The mechanisms of filter feeding: some theoretical considerations. Amer. Natur. 111, 981-994. 
Sanderson, S.L., Cech, Jr., J.J., 1995. Particle retention during respiration and particulate feeding in the suspension-feeding blackfish, Orthodon microlepidotus. Can. J. Fish. Aquat. Sci. 52, 2534-2542.

Sanderson, S.L., Cech, Jr., J.J., Patterson, M.R., 1991. Fluid dynamics in suspension-feeding blackfish. Science 251, 1346-1348.

Sanderson, S.L., Cheer, A.Y., Goodrich, J.S., Graziano, J.D., Callan, W.T., 2001 . Crossflow filtration in suspension-feeding fishes. Nature 412, 439-441.

Sanderson, S.L., Mort, M.E., Cech, Jr., J.J., 1998. Particle retention by non-suspension-feeding cyprinid fishes. Can. J. Fish. Aquat. Sci. 55, 861-868.

Sanderson, S.L., Stebar, M.C., Ackermann, K.L., Jones, S.H., Batjakas, I.E., Kaufman, L., 1996. Mucus entrapment of particles by a suspension-feeding tilapia (Pisces: Cichlidae). J. Exp. Biol. 199, 1743-1756.

Sanderson, S.L., Wassersug, R., 1990. Suspension-feeding vertebrates. Sci. Amer. 262, 96-101. Schaus, M.H., Godwin, W., Battoe, L., Coyeney, M., Lowe, E., Roth, R., Hawkins, C., Vindigni, M., Weinberg, C., Zimmerman, A., 2010. Impact of the removal of gizzard shad (Dorosoma cepedianum) on nutrient cycles in Lake Apopka, Florida. Freshw. Biol. 55, 2401-2413.

Seghers, B.H., 1975. Role of gill rakers in size-selective predation by lake whitefish, Coregonus clupeaformis (Mitchill). Verh. Internat. Verein. Limnol. 19, 2401-2405.

Segré, G., Silberberg, A., 1962. Behaviour of macroscopic rigid spheres in Poiseuille flow. Part 2. Experimental results and interpretation. J. Fluid. Mech. 14, 136-157.

Shephard, K.L., 1994. Functions for fish mucus. Rev. Fish Biol. Fish. 4, 401-429.

Shimeta, J., Jumars, P.A., 1991. Physical mechanisms and rates of particle capture by suspension-feeders. Ocean. Mar. Biol. Ann. Rev. 29, 191-257. 
Shoup, D.E., Hill, L.G., 1997. Ecomorphological diet predictions: an assessment using inland silverside (Menidia beryllina) and longear sunfish (Lepomis megalotis) from Lake Texoma. Hydrobiologia 350, 87-98.

Smith, J.C., Sanderson, S.L., 2007. Mucus function and crossflow filtration in a fish with gill rakers removed versus intact. J. Exp. Biol. 210, 2706-2713.

Smith, J.C., Sanderson, S.L., 2008. Intra-oral flow patterns and speeds in a suspension-feeding fish with gill rakers removed versus intact. Biol. Bull. 215, 309-318.

Spataru, P., Zorn, M., 1978. Food and feeding habits of Tilapia aurea (Steindachner) (Cichlidae) in Lake Kinneret (Israel). Aquaculture 13, 67-79.

Vinyard, G.L., Drenner, R.W., Gophen, M., Pollingher, U., Winkelman, D.L., Hambright, K.D., 1988. An experimental study of the plankton community impacts of two omnivorous filterfeeding cichlids, Tilapia galilaea and Tilapia aurea.Can. J. Fish. Aquat. Sci. 45, 685-690.

Wright, D.I., O'Brien, W.J., Luecke, C., 1983. A rew estimate of zooplankton retention by gill rakers and its ecological significance. Tráns. Am. Fish. Soc. 112, 638-646.

Yowell, D.W., Vinyard, G.L., 1993. An energy-based analysis of particulate-feeding and filterfeeding by blue tilapia, Tilapia aurea. Env. Biol. Fish. 36, 65-72. 

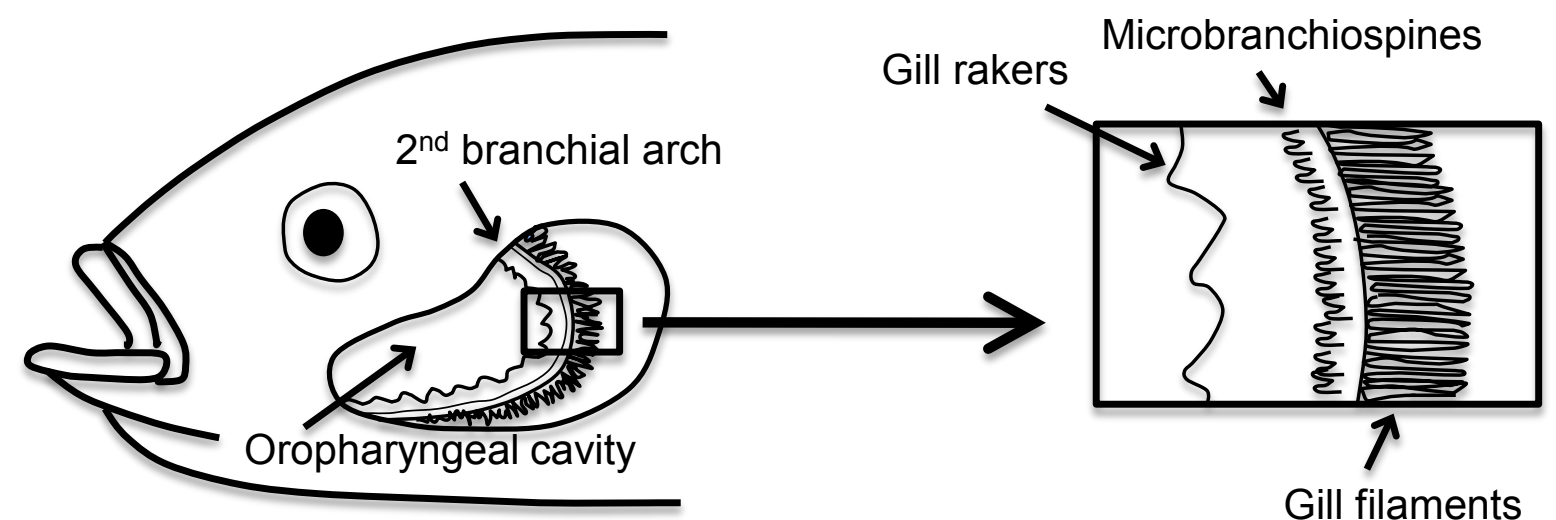

Fig. 1. Lateral row of gill rakers and microbranchiospines on the second branchial arch from the left side of a suspension-feeding cichlid fish. Left gill cover (operculum) and branchial arches 1, 3,

4 , and 5 have been removed to show orientation of the branchial arches inside the oropharyngeal cavity. Box has been enlarged at right to illustrate gill rakers and microbranchiospines on the branchial arch. 

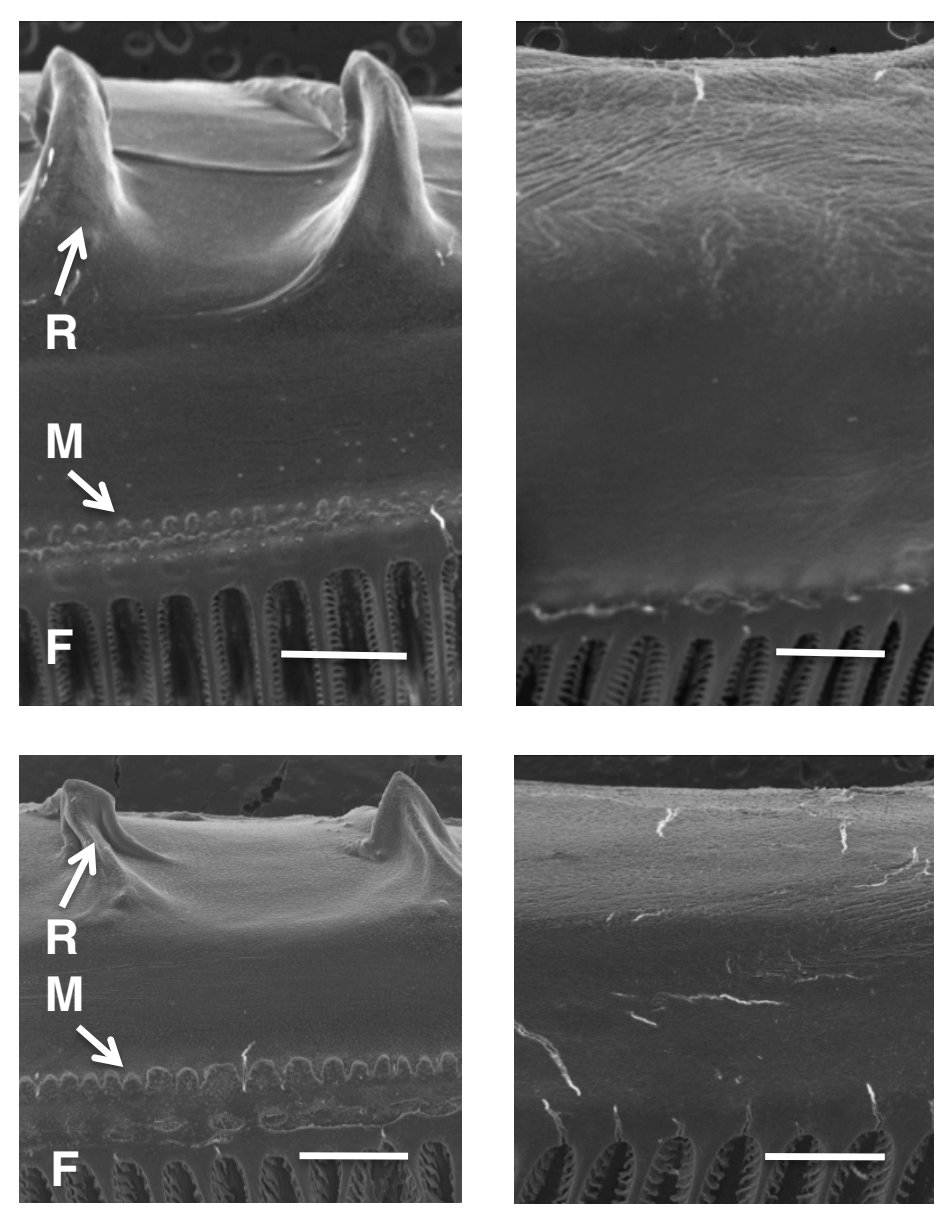

Fig. 2. Scanning electron micrographs showing lateral surface of second gill arch in Oreochromis aureus (top) and Oreochromis esculentus (bottom), with gill rakers and microbranchiospines intact (left) or removed (right). Specimens prepared 15 days after gill rakers and microbranchiospines were removed from the right side of each fish only. R, gill raker; M, microbranchiospines; F, gill filaments; scale bars $=500 \mu \mathrm{m}$. 


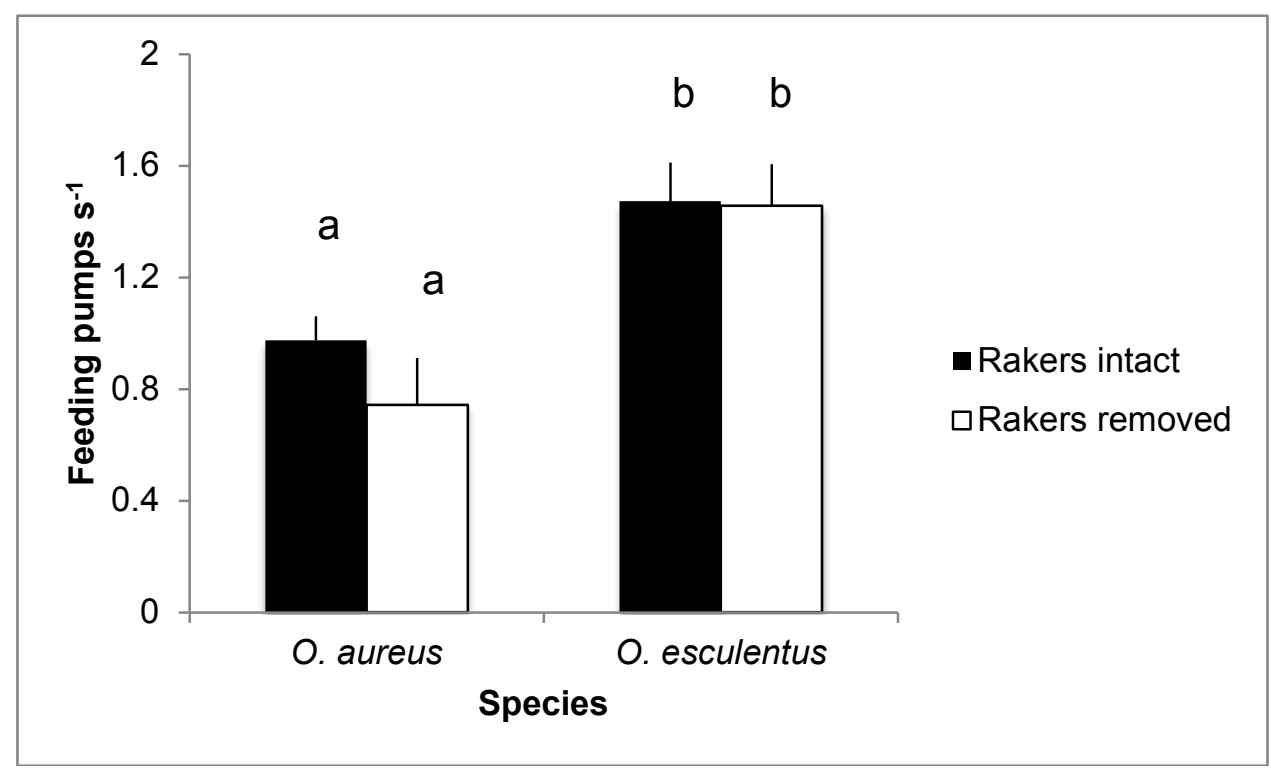

Fig. 3. Rate of feeding pumps in Oreochromis aureus and O. esculentus with gill rakers and microbranchiospines intact versus removed (mean \pm S.D., $\mathrm{n}=3$ ). Different letters show significant differences (repeated measures ANOVA, $P=$ $0.003)$. 


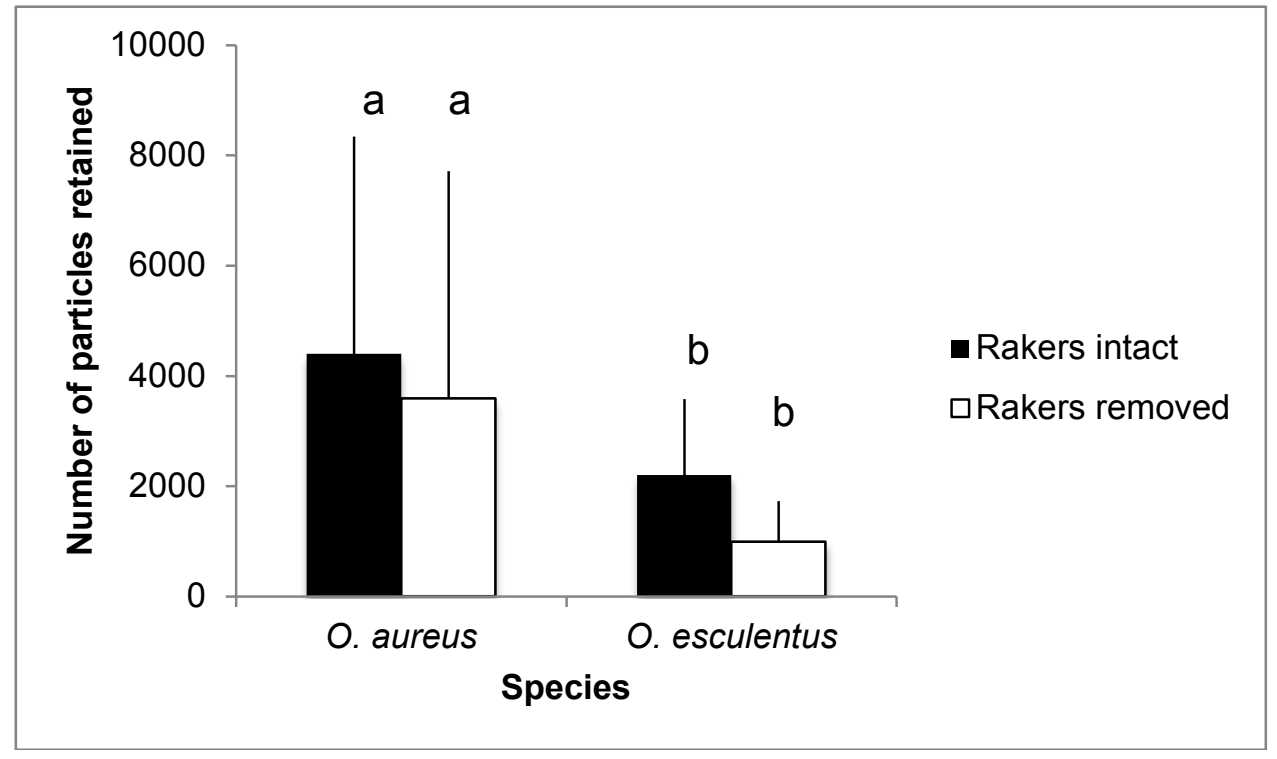

Fig. 4. Number of microspheres retained by Oreochromis aureus and $O$. esculentus with gill rakers and microbranchiospines intact versus removed (mean \pm S.D., $n=3$ ). Different letters show significant differences (repeated measures ANOVA, $P=0.03)$. 

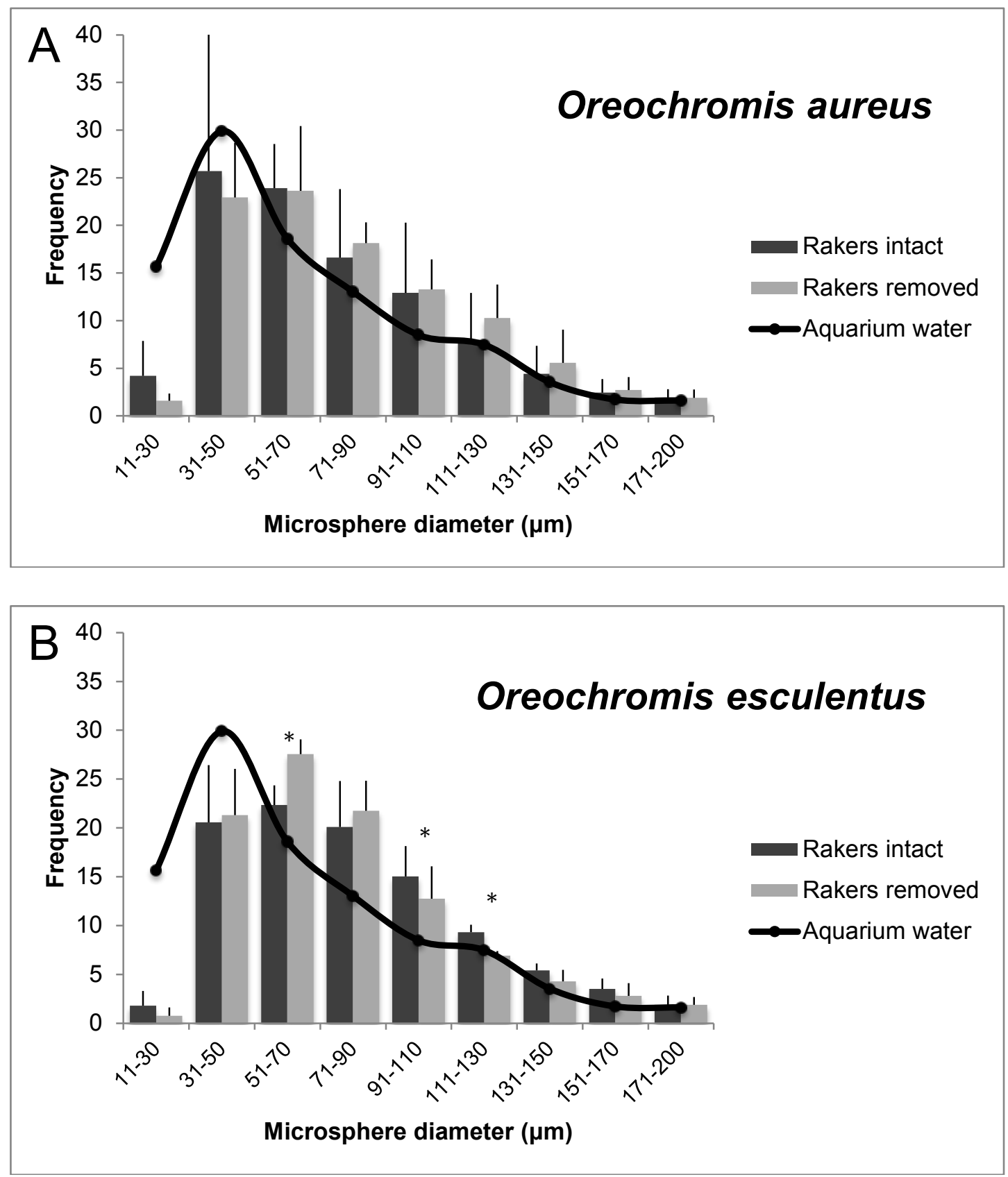

Fig. 5. The size frequency distributions of microspheres retained by Oreochromis aureus (A) and O. esculentus (B) before gill raker and microbranchiospine removal and after removal differed significantly from the size frequency distribution in the aquarium water during the feeding experiments (replicated goodness of fit tests, $P<0.001, \mathrm{n}=5$ ). Oreochromis esculentus retained a significantly higher proportion of 51-70 $\mu \mathrm{m}$ microspheres and a significantly lower proportion of 91-130 $\mu \mathrm{m}$ microspheres following gill raker and microbranchiospine removal compared with retention when these structures were intact (asterisks, Kolmogorov-Smirnov test, $P<0.01, \mathrm{n}=5$ ). 